\title{
DYNAMIC BEHAVIOUR OF DIFFERENT HYDRAULIC DRIVE CONCEPTS - COMPARISON AND LIMITS
}

\author{
Lovrec, D. ; Tic, V. ${ }^{*} \&$ Tasner, T. ${ }^{* *}$ \\ *University of Maribor, Faculty of Mechanical Engineering, Smetanova 17, Maribor, Slovenia \\ ** HAWE Hidravlika d.o.o., Petrovče 225, Petrovče, Slovenia \\ E-Mail: darko.lovrec@um.si,vito.tic@um.si, t.tasner@hawe.si
}

\begin{abstract}
Improvement in regard to machine energy efficiency is one of the more important goals throughout all fields of research. This is especially true for hydraulically driven machines with large installed power. The use of the appropriate drive concepts, along with a suitable control concept, can result in quite substantial energy savings. Equipping a hydraulic machine with a speed-variable drive and a variable displacement pump enables maximum efficiency tracking for all operating points, represents the most promising drive concept in regard to energy savings. For each operating point, there is an optimal pump setting; consequently, the hydraulic system is able to ensure hydraulic power with minimum losses if the drive components are selected thoughtfully and the system controlled properly. However, in the desire to maximise the system efficiency, the system's responsiveness is too often overlooked.

The paper summarises the principle of different drive concepts, along with the drive controller, in terms of the dynamic response and the drive efficiency. Although the speed-variable drive concepts are the most efficient, they have some disadvantages, which are also presented.

(Received in December 2016, accepted in May 2017. This paper was with the authors 2 months for 2 revisions.)
\end{abstract}

Key Words: Hydraulic, Power Unit, Drive Concepts, Control Strategies, Simulation, Dynamic

\section{INTRODUCTION}

Machines that require intense forces for their operations are powered mainly by hydraulic drives. Intense forces, especially when combined with high speeds, result in high power requirements that are reflected in high-energy consumption. Even the slightest (at the percentage level) optimisations regarding the energy efficiencies of such machines, result in significant savings over long operating periods. Therefore, improved efficiency and reduced energy consumption are two of the main goals during the design periods of modern electrohydraulic systems.

Most machines are still using the classic drive concept: A constant volume pump or, as a better solution, the usage of a variant variable displacement pump, in both cases driven at constant speed. The requirement for greater robustness, taking into account the reasonable price, have led to usage of the speed controlled constant pumps. However, such a concept cannot meet the dynamic requirements of the classic drive concept.

The more effective approach, to adapt the supply energy to the actual needs of the actuator(s) or load, offers the combination of a variable pump and a speed-adjustable electric motor. Within this drive concept, two parameters need to be adjusted: The rotational speed of the electric motor and the displacement volume of the used variable pump as well. All three mentioned adaptive supply principles with main properties are shown in Fig. 1.

More information regarding the detailed drive design, including the specified type and characteristics of used components, along with its efficiency, reliability, robustness, operating costs, purchase price, has been the subject of various research, e.g. [1-7]. The same applies to studies related to the use of a wide range of control concepts and control strategies, from classical to non-linear approaches that have proven to be effective on hydraulic or other types of drives, e.g. [8-14]. In studies, the focus was on efficiency of a specified drive concept, at different operating points, but with less attention to its dynamics. 


\begin{tabular}{|c|c|c|c|}
\hline & $\begin{array}{c}\text { CV-drive concept } \\
\text { asynchronous motor } \\
\text { variable axial piston pump }\end{array}$ & $\begin{array}{c}\text { VC-drive concept } \\
\text { variable frequency drive } \\
\text { controller } \\
\text { asynchronous motor } \\
\text { constant gear pump }\end{array}$ & $\begin{array}{c}\text { VV-drive concept } \\
\text { variable frequency drive } \\
\text { controller } \\
\text { asynchronous motor } \\
\text { variable axial piston pump } \\
\text { putational speed }\end{array}$ \\
\hline $\begin{array}{c}\text { pump's } \\
\text { displacement }\end{array}$ & constant & variable & variable \\
\hline scheme & $P_{e l}$ & variable
\end{tabular}

Figure 1: Three different electrohydraulic variable supply concepts in comparison.

\section{DYNAMICAL BEHAVIOUR OF DRIVE CONCEPTS}

In addition to the efficiency at steady state operating points, it is reasonable to examine the dynamics and efficiency of drive concepts for different working cycles that are similar to the working cycle in hydraulic machines. Working cycles commonly contain step-changes; more and more machines must also follow a specific working/operating profile. For such purpose, a so-called combined operating cycle has been chosen. The combined cycle combines different types of changes in one cycle. Such cycle includes a step change, a ramp and sinusoidal profile of the pressure set-point. Fig. 2 shows the pressure set-point vs. time plot of the combined cycle.

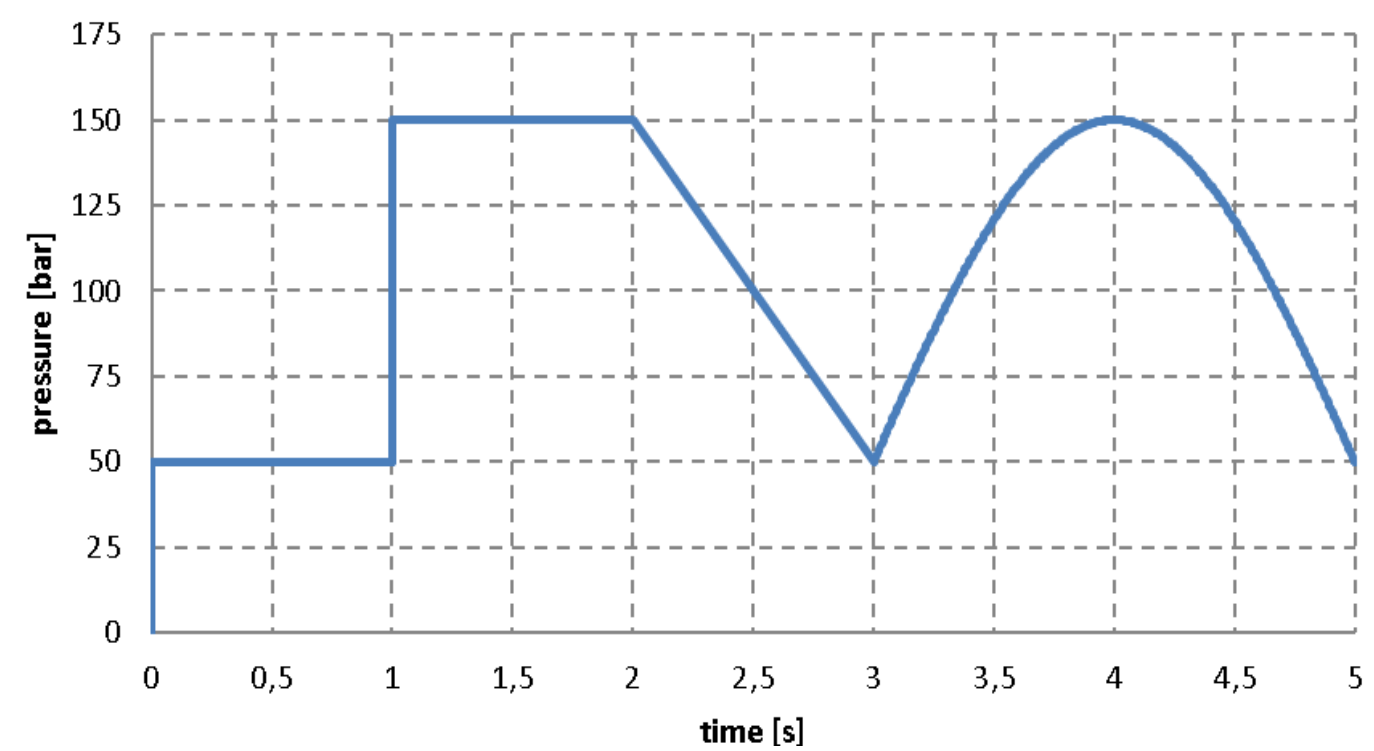

Figure 2: Pressure set-point vs. time plot of the combined operating cycle.

While the machine follows the combined cycle, the following physical quantities are being measured: 
- Total energy used $W$ (using a current clamp meter connected to the electrical network before a variable frequency drive controller),

- Energy used by the asynchronous motor $W_{e l}$ (using a current clamp meter between the motor and the variable frequency drive controller),

- Mechanical power of the motor (calculated by multiplying rotational speed $n$ and torque $M$ of the motor (both parameters acquired from analogue outputs of the variable frequency drive controller),

- Pump setting $\alpha$ (acquired from the pump's control card analogue output),

- Hydraulic power (as a product of flow $Q$ and pressure $p$ ).

The controller itself acquires most of the physical quantities. Data from instruments without analogue or digital outputs are appended manually.

\subsection{Constant speed asynchronous motor and variable piston pump - CV-drive concept}

Despite many modern control techniques, the CV-drive concept uses a traditional PID controller. The PID controller adjusts the pump's displacement based on the difference between actual pressure and the pressure set-point. A block diagram of the CV-drive concept with PID controller is shown in Fig. 3.

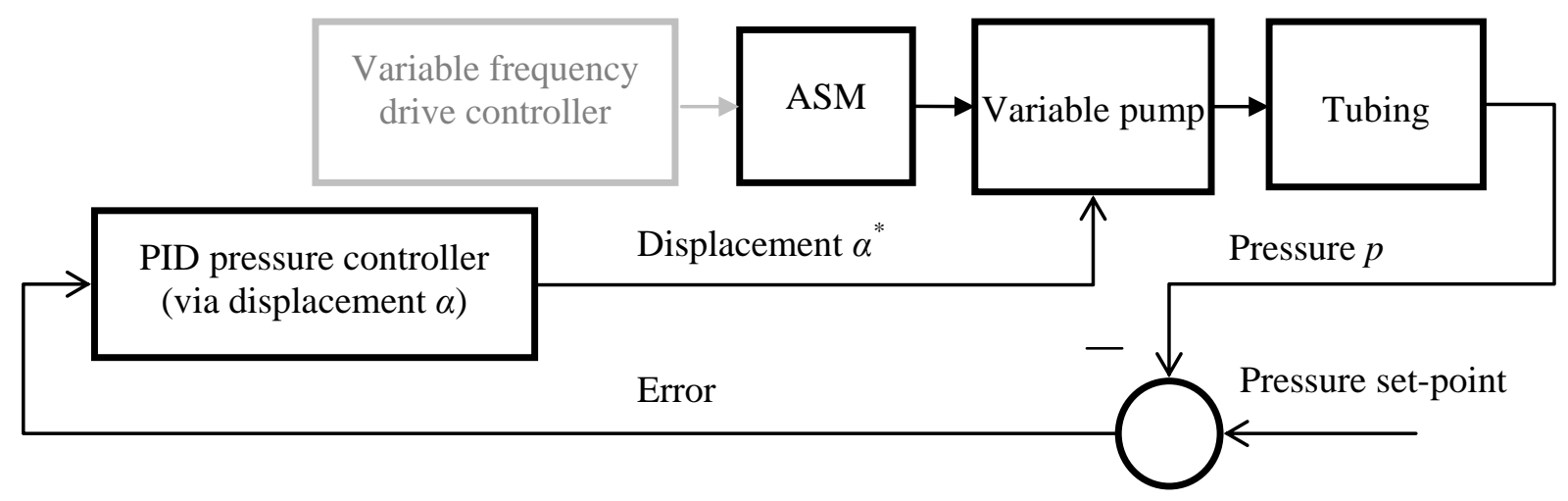

Figure 3: Block diagram of CV-drive concept with PID controller.

The presented control strategy, based on the CV-drive concept, has been evaluated using simulation and experiment. Fig. 4 shows responses acquired from simulation (green) and measurement (red), whereas the pressure set point is depicted with a blue line. It can be seen that the simulation and experiment show very similar behaviour, while the biggest difference is the step response from 0 to 50 bar.

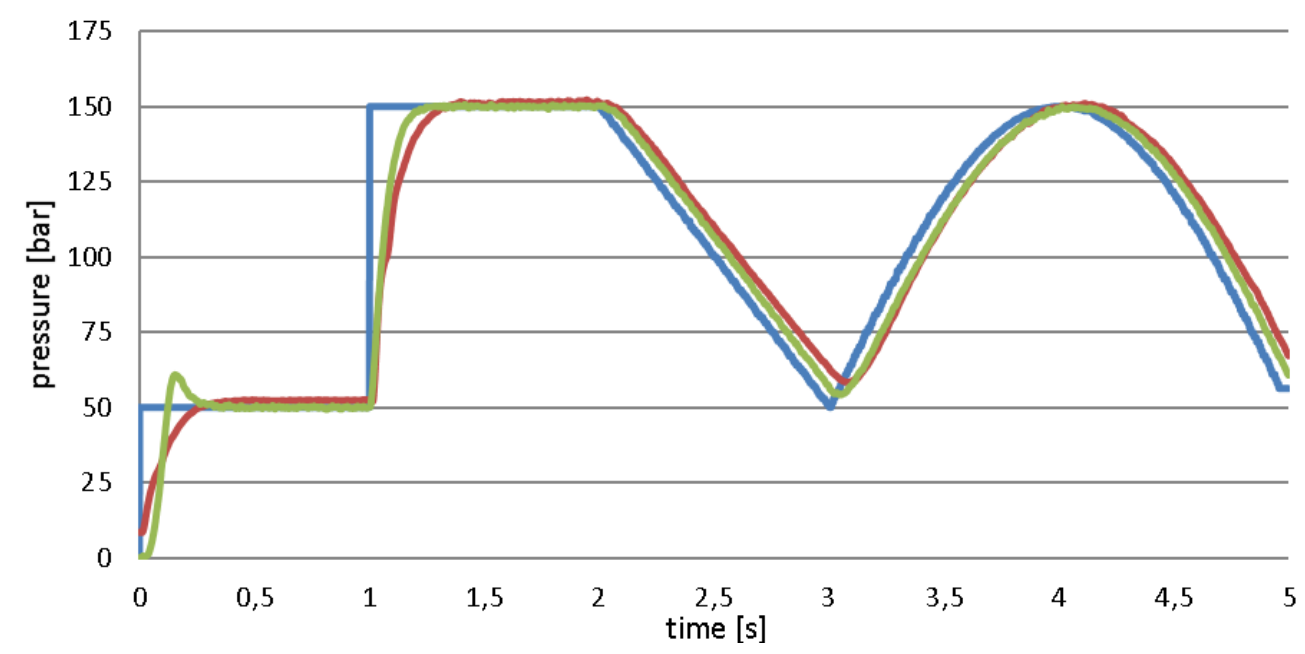

Figure 4: Response of CV-drive concept with PID controller to the combined cycle. 


\subsection{Frequency driven asynchronous motor and gear pump - VC-drive concept}

Similar to the CV-drive concept, the VC-drive concept is used commonly in combination with a PID controller. The PID controller controls the system pressure by varying the motor`s (and, consequently, the pump's) rotational speed using the variable frequency drive controller. Fig. 5 shows a block diagram of such a control strategy based on the VC-drive concept.

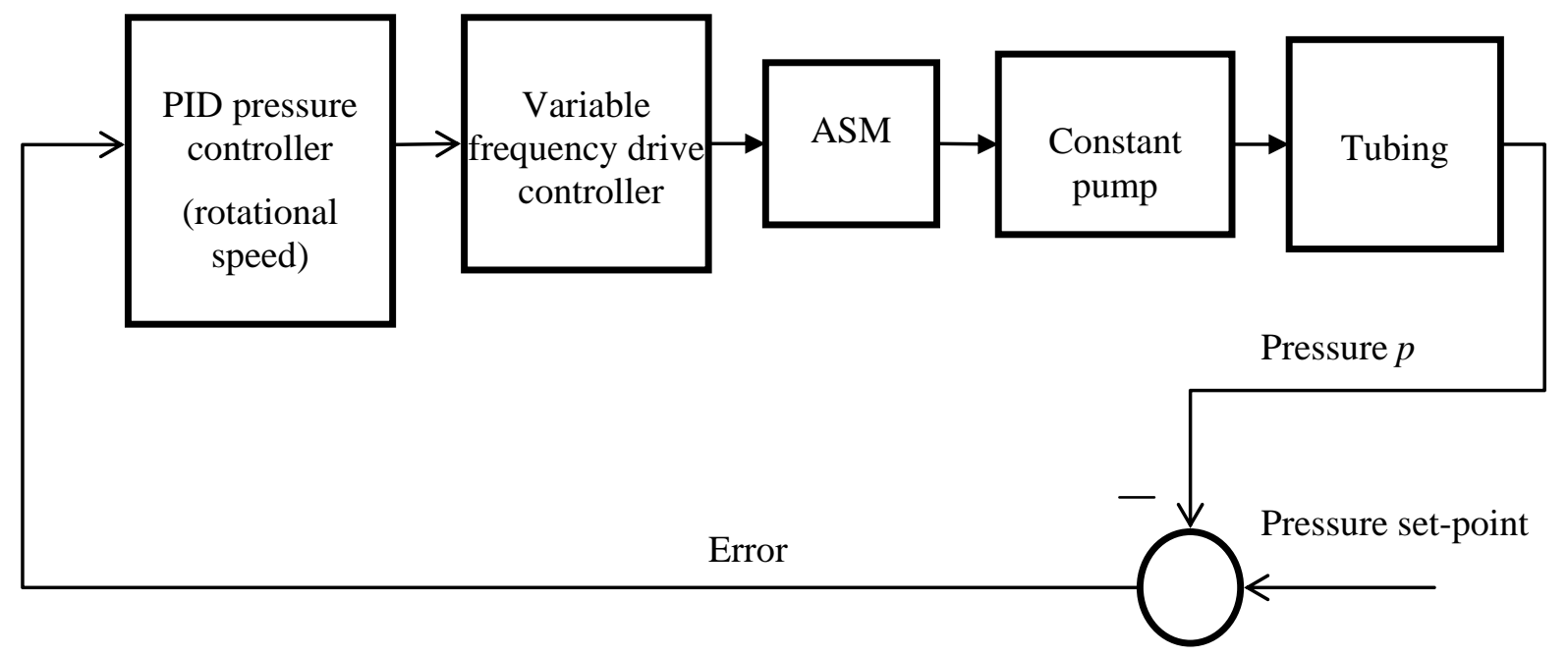

Figure 5: Block diagram of VC-drive concept with PID controller.

The presented control strategy, based on the VC-drive concept, was evaluated using simulation and experiment. Fig. 6 shows responses acquired from simulation (green) and measurement (red), whereas the pressure set-point is shown in blue. Detailed information related to the simulation is available in the literature $[7,13,15-20]$.

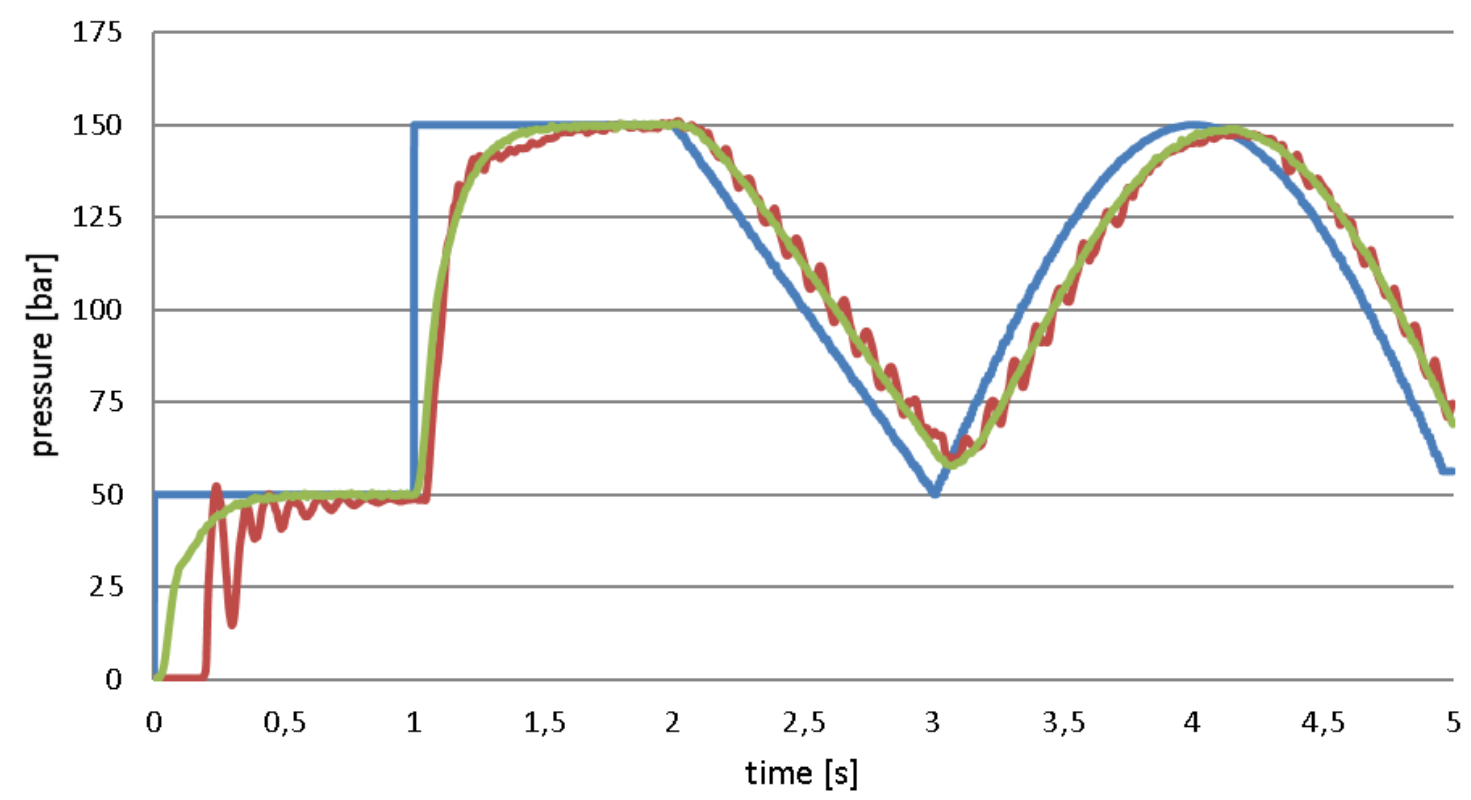

Figure 6: Response of VC-drive concept with gear pump and PID controller.

A similar conclusion about the dynamics can be made in the case of the use of a variable axial piston pump set to maximal displacement (VC-APP-drive concept). Asynchronous motor dynamics have the biggest influence on the control accuracy, and especially the drive dynamic. The reasons for the minor differences in the responsiveness of the system are in the different moments of inertia of both pumps`variants. 


\subsection{Frequency driven asynchronous motor and variable pump - VV-drive concept}

The drive concept VV is currently rarely in use, due to the problem of multivariable control. Two variables can be changed - displacement of the pump and rotational speed of the motor. The straightforward solution is to merge the control strategies of CV-and VC-drive concepts. Such a merger results in a new control strategy using two PID controllers - "PID".

If the highest dynamics are required, rotational speed has to be set to maximal, while pump displacement adjusts to changes in flow. This argument can be proven easily, assuming the VV-drive concept is maintaining correct pressure at $30 \%$ of rotational speed and $90 \%$ of maximal displacement. A load is switched on which multiplies the flow by two, and the pressure therefore drops. The pump cannot supply enough flow to keep the pressure up, which causes the motor to accelerate, which is a lot slower compared to pump setting change due to high moments of inertia.

Although higher dynamics (compared to the CV-concept) concept cannot be achieved with the VV-drive, the VV-drive concept enables maximum efficiency tracking. Maximum efficiency of the current operating point (pressure, flow) is achieved with only one combination of displacement and rotational speed. Such problem can be solved using a special control strategy, based on the maximum efficiency controller, which, together with the VV drive concept, forms the so called $\eta$-drive concept.

When synthesising the PID $^{2}$ control strategy a question arises, whether both PID controllers will act accordingly, or will they oppose each other, which could lead to instabilities (Fig. 7). The performed simulation and experiments showed that both controllers always acted accordingly, but exposed another weakness of such control strategy - we don't have any influence on either dynamics or efficiency. The control strategy stays at the same operating point with random combination of rotational speed and pump setting. That causes the system to behave differently in each simulation / experiment.

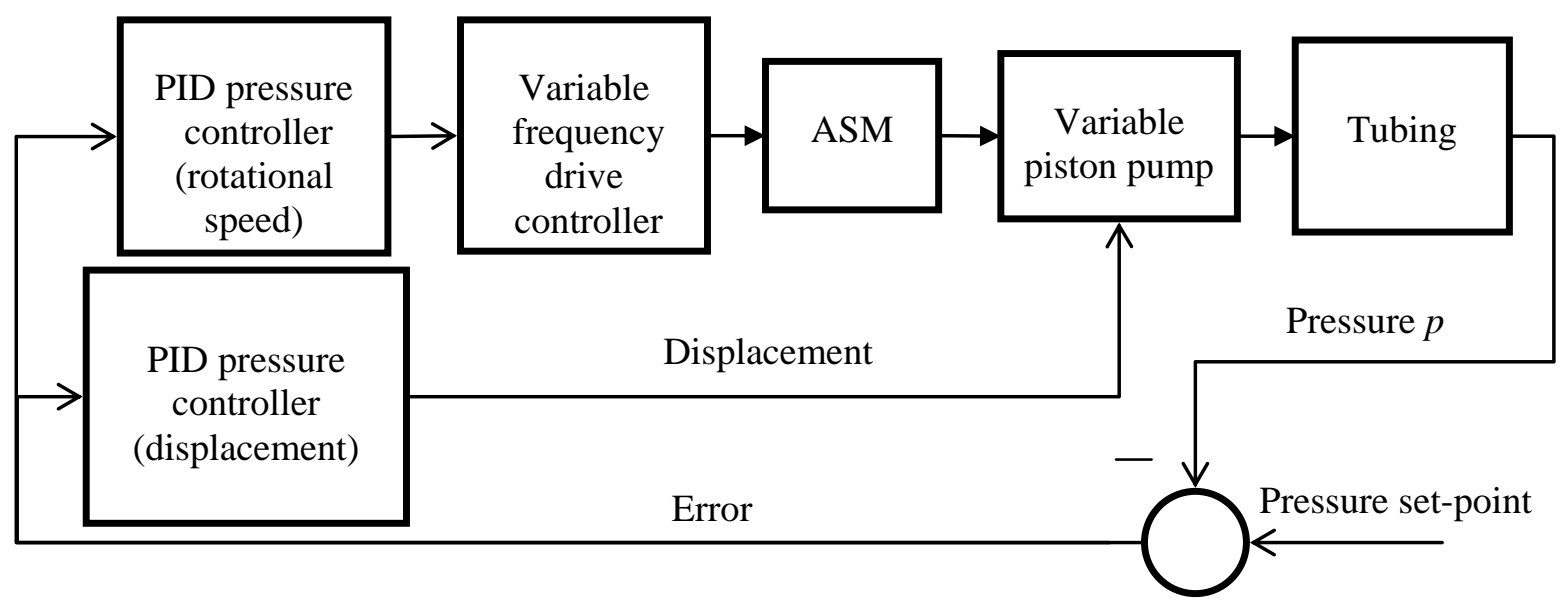

Figure 7: Block diagram of VV-drive concept with PID $^{2}$ controller.

The presented control strategy with two PID controllers, based on the VV-drive concept, was evaluated using simulation and experiment. Fig. 8 shows the responses acquired from simulation (green) and measurement (red), whereas the pressure set-point is shown in blue. Similarly to both previous control strategies, the results obtained using simulation and experiment are comparable. The higher dynamics of such a system can be noticed, especially at the step change from 50 to 150 bar. Moreover, such system can track a ramp and sine easier than both previous systems. 


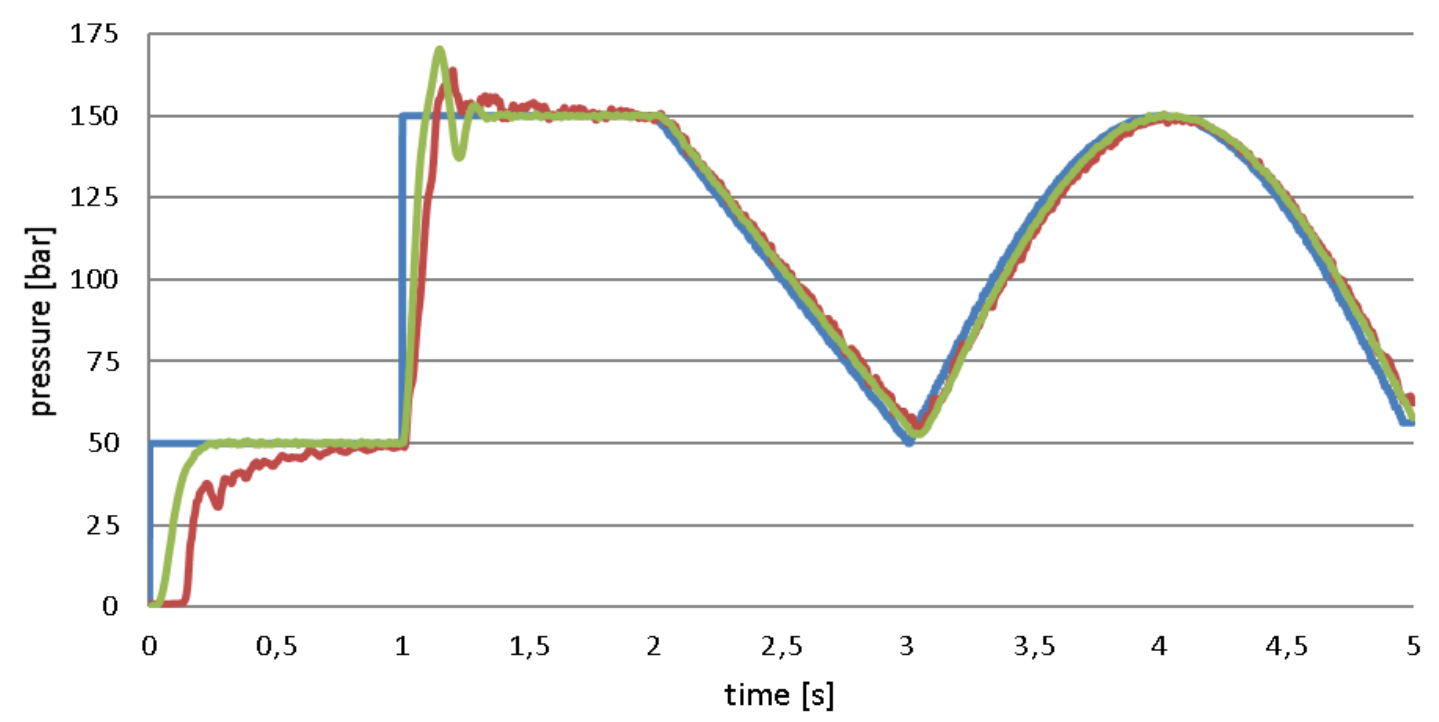

Figure 8: Response of VV-drive concept with $\mathrm{PID}^{2}$ controller to the combined cycle.

\section{COMPARISION OF DYNAMICS AND EFFICIENCY}

To compare different drive concepts, the comparison criteria need to be chosen. The most sensible is to compare the efficiency. However, since all the drive concepts do not follow the pressure set-point the same way, it is necessary to compare the included control error - the difference between the pressure set-point and the actual pressure. This can best be done by calculating the root mean squared error according Eq. (1), since it eliminates the influence of the sign of the error.

Because the pressure waveform is different, supplied hydraulic energy is also not the same for all concepts, so it makes sense to add the consumed electrical and supplied hydraulic energy to the list. A lot of information of the dynamics of each concept is hidden in overshoot and setup time of the step change. Overshoot is defined as the maximum excess of the desired value of; set-time as the time that elapses from the initiation until the actual value reaches and remains within $5 \%$ of the desired value. The comparison will include both parameters at a step change from 50 to 150 bar.

$$
R M S E=\sqrt{\frac{\sum_{i=1}^{n}\left(p^{*}(i)-p(i)\right)^{2}}{n}}
$$

where:

RMSE [bar].- root mean square error,

$n \quad[-] \quad$ - number of pressure measurements,

$p^{*}(i) \quad$ [bar].- pressure set-point of $i^{\text {th }}$ measurement,

$p(i) \quad[\mathrm{bar}] .-$ actual pressure of $i^{\text {th }}$ measurement.

To increase ease of comparison, all the criteria will be combined using weighted average, which will result in a numeric score. All the criteria, including weights, are shown in Table I.

The best scores in each category are indicated in Table II. The percentages for all criteria are weighted, summed and displayed in the last column of Table II.

The consumed electricity and the supplied hydraulic energy has been measured over 50 consecutive cycles, which improves the accuracy of the measurements, as a cycle lasts for only $5 \mathrm{~s}$. The average yield was calculated as the quotient between the produced and consumed energy. Both form of energies quoted in Table II refer to one cycle. RMSE was calculated for the entire cycle and only sinusoidal change (3 to $5 \mathrm{~s}$ ). For the second step, 
settling time and overshoot were calculated. A close-up view of step changes of all the concepts is presented in Fig. 9.

Table I: Weights and criteria for comparing different drive concepts.

\begin{tabular}{|l|c|c|c|c|c|c|c|}
\hline Category & \multicolumn{3}{|c|}{ Energy } & \multicolumn{3}{c|}{ Dynamics } \\
\cline { 2 - 8 } $\begin{array}{l}\text { Category } \\
\text { weight }\end{array}$ & \multicolumn{3}{|c|}{$60 \%$} & \multicolumn{3}{c|}{$40 \%$} \\
\hline Criterion & $\begin{array}{c}\text { Average } \\
\text { efficiency }\end{array}$ & $\begin{array}{c}\text { Consumed } \\
\text { electricity }\end{array}$ & $\begin{array}{c}\text { Supplied } \\
\text { hydraulic } \\
\text { energy }\end{array}$ & $\begin{array}{c}\text { Total } \\
R M S E\end{array}$ & $\begin{array}{c}\text { Sine } \\
R M S E\end{array}$ & $\begin{array}{c}\text { Settling } \\
\text { time }\end{array}$ & Overshoot \\
\hline $\begin{array}{l}\text { Weights in- } \\
\text { side category }\end{array}$ & $50 \%$ & $30 \%$ & $20 \%$ & $60 \%$ & $20 \%$ & $10 \%$ & $10 \%$ \\
\hline Final weights & $30 \%$ & $18 \%$ & $12 \%$ & $24 \%$ & $8 \%$ & $4 \%$ & $4 \%$ \\
\hline
\end{tabular}

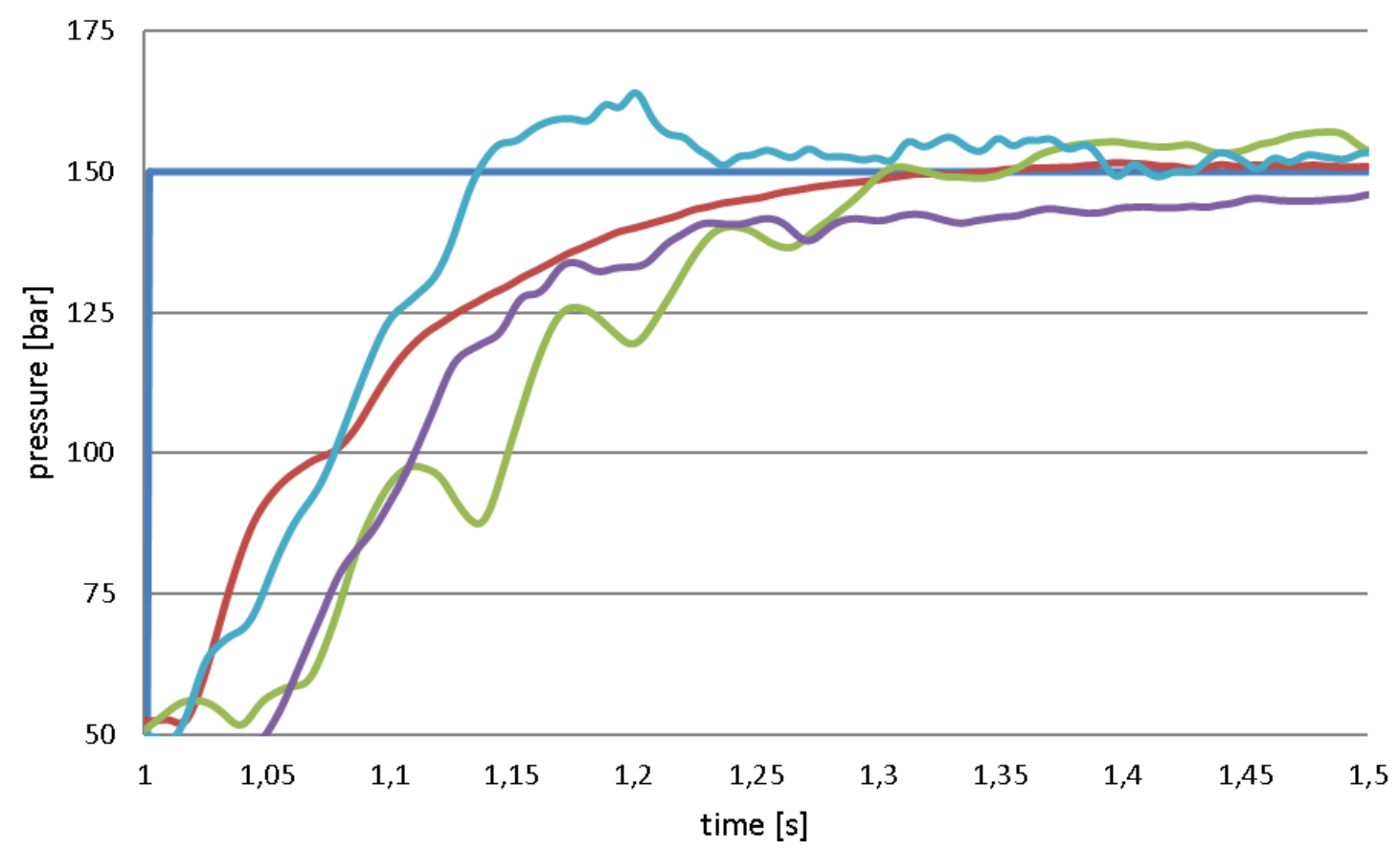

Figure 9: Comparison of step responses (from 50 to 150 bar) for different drive concepts: CV (red), VC (green), VC-APP (violet), VV (cyan)

Table II: Measurement results of dynamics of different drive concepts.

\begin{tabular}{|c|c|c|c|c|c|c|c|c|}
\hline Concept & $\begin{array}{c}\text { Average } \\
\text { efficiency }\end{array}$ & $\begin{array}{c}\text { Consumed } \\
\text { electricity } \\
{[\mathrm{kJ}]}\end{array}$ & $\begin{array}{c}\text { Supplied } \\
\text { hydraulic } \\
\text { energy } \\
{[\mathrm{kJ}]}\end{array}$ & $\begin{array}{c}\text { Total } \\
R M S E \\
{[\mathrm{bar}]}\end{array}$ & $\begin{array}{c}\text { Sine } \\
R M S E \\
{[\mathrm{bar}]}\end{array}$ & $\begin{array}{c}\text { Settling } \\
\text { time } \\
{[\mathrm{s}]}\end{array}$ & $\begin{array}{c}\text { Over- } \\
\text { shoot } \\
{[\mathrm{bar}]}\end{array}$ & Total \\
\hline $\begin{array}{c}\text { CV } \\
\text { (red) }\end{array}$ & $57,7 \%$ & 46,2 & 26,7 & 12,55 & 8,10 & 0,22 & 1,63 & $94,0 \%$ \\
\hline VC (green) & $56,9 \%$ & 45,4 & 25,8 & 21,22 & 14,42 & 0,28 & 7,07 & $79,7 \%$ \\
\hline $\begin{array}{c}\text { VC-APP } \\
\text { (violet) }\end{array}$ & $57,5 \%$ & 46,0 & 26,5 & 19,79 & 12,56 & 0,36 & 0 & $83,1 \%$ \\
\hline $\begin{array}{c}\text { VV } \\
\text { (cyan) }\end{array}$ & $53,6 \%$ & 47,5 & 25,5 & 14,49 & 4,45 & 0,13 & 14,00 & $89,3 \%$ \\
\hline
\end{tabular}

Based on the average efficiency all the drive concepts perform similarly. The least efficient was the VV-drive concept with PID $^{2}$ controller. The smaller average efficiency is due to non-optimal setting of the pump setting, and the unneeded acceleration and braking of 
the rotating parts. Although the desired pressures for all the concepts are the same, the produced hydraulic energy differs throughout different concepts, due to different control strategies. Concepts with lower dynamics produced less hydraulic power.

The ability to trace the desired profile is higher when using a variable displacement pump. RMSE is there more than 3-times lower. The dynamics of the systems are similar; VV-drive concept, which has for one-third the shortest settling time times with little higher overshoot. We were surprised that the dynamics (short settling time) of the drive concepts using a variable displacement pump were only 3-times higher, compared to those using a constant pump, whereas the literature states 4-times higher dynamics [3, 15]. The case for such difference could be noise on the pressure signal, which prevented us from attenuating the controller parameters further.

\section{LIMITATIONS AND FURTHER IMPROVEMENTS}

One of the disadvantages of the speed variable drive concepts, based on the use of an induction (ASM - asynhronous) electric motor, is motor acceleration and deceleration for short pressure bursts. If a valve opens for 1 second, for example, the motor starts to accelerate to increase pressure and, after 1 second, has to decelerate again as the pressure is too high because the valve has closed again. Every acceleration and deceleration using electromotors results in higher current, which yields higher copper losses, where energy from decelerating rotating masses can be regenerated when using a state-of-the-art variable frequency drive controller. It is easily avoidable by adding a hydraulic accumulator to the hydraulic circuit, which smooths short pressure bursts and aids the motor and pump in their battles with rapid pressure changes [7].

From the drive component point of view, instead of usage of a frequency controlled asynhronous motor, a much better variant represents the usage of a speed-controlled electric servo motor. Due to its smaller inertia, its reponsiveness is much better.

On the signal side, in respect to the control concept, the further improvement in regard to the energy efficiency is the implementation of an advanced control strategy, e.g. the usage of the s.c. $\eta$-drive concept or maximum effuciency drive concept, which is based on the VVdrive concept [21]. A block diagram of such concept is shown in Fig. 10.

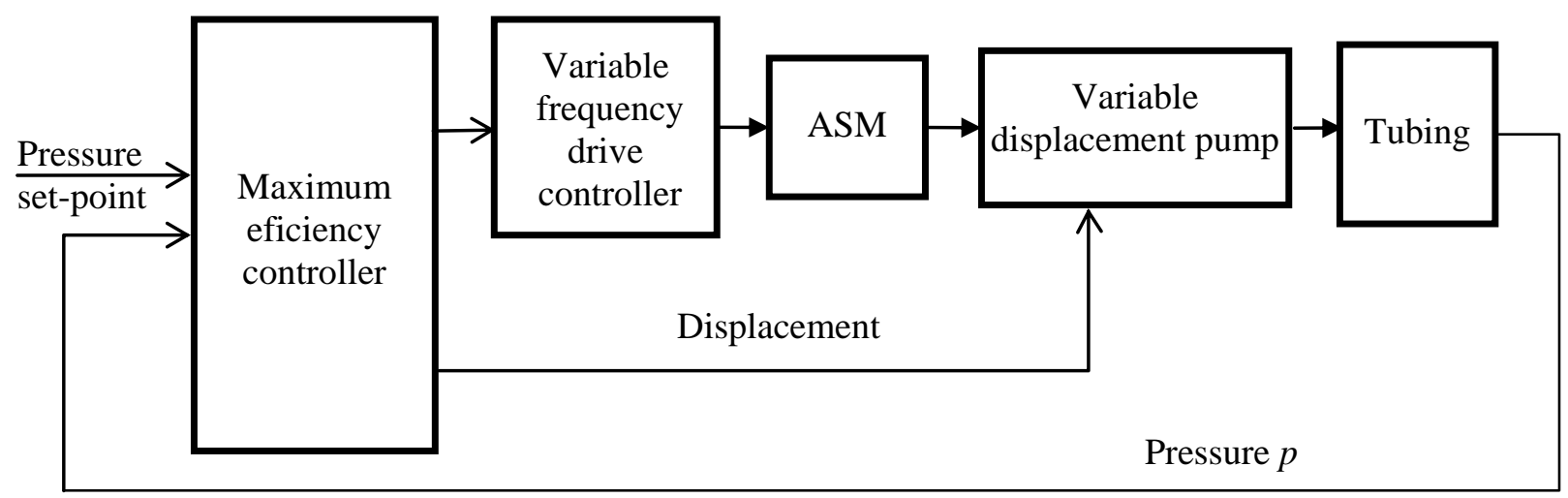

Figure 10: Block diagram of VV-drive concept with $\eta$-drive strategy.

The heart of the $\eta$-drive concept is a maximum efficiency controller. The maximum efficiency controller controls the pump's displacement and rotational speed of the asynchronous motor using the variable frequency drive controller.

The maximum efficiency controller is based on a combination of a Look-up Table and a classic PID controller. The PID controller is used to control the displacement of the axial piston pump. The advantages of using a PID controller for displacement control are 
elimination of steady state error, fast response to rapid pressure changes and the ability to track pressure when the rotational speed of the motor is changing to the optimum.

The next limitation when implementing the variable drive concept is at those operating points where the best efficiencies are achieved at pump settings close to $100 \%$. A Look-up Table that reports the best rotational speed at which a pump setting of higher than $100 \%$ would be needed to reach the pressure set-point. This error can arise due to fluid changes, temperature changes, wear or Look-up Table smoothing during calculation. To avoid this limitation, a feedforward loop for rotational speed should be added to increase rotational speed further if the desired pressure set-point cannot be reached with a $100 \%$ pump setting.

Further improvement can be made for machines with cyclic operational cycles, where the pressure cycle or load demands are repeating throughout the machines' operations. The pressure changes in this case can be predicted in advance. Therefore, it would be reasonable to couple the maximum efficiency controller with the Model Predictive Controller (MPC), which has already proved to be very useful for machines with repeating operation cycles.

\section{CONCLUSION}

Different variable hydraulic supply systems are presented in the paper, from the basic drive concept, a combination of variable pump driven by constant speed, until drive concept with variable pump driven by variable speed. In connection with variable drive concepts, different control strategies have been implemented, from the usage of classical PID controller all the way the bi-variable control concept, using the maximum efficiency strategy - the $\eta$-drive concept. It has been shown that the $\eta$ drive concept can be used on any hydraulic machine with variable drive speed and variable displacement; in principle, it can be either electric or fuel powered.

Except for energy considerations of different drive concepts to adapt to the needs of the consumer, the dynamics of the individual drive concept were at the forefront of the research. The comparison of dynamic was based at a combined working cycle. the $\eta$ drive concept has similar efficiency to the classic drive concept, although it uses a variable frequency drive controller that adds additional losses to the system. Some limitations and disadvantages have also been presented with possible solutions and workarounds.

\section{REFERENCES}

[1] Xu, M.; Jin, B.; Chen, G.; Ni, J. (2013). Speed-control of energy regulation based variable-speed electrohydraulic drive, Strojniski vestnik - Journal of Mechanical Engineering, Vol. 59, No. 7-8, 433-442, doi:10.5545/sv-jme.2012.911

[2] Ferreira, F. J. T. E.; Fong, J. A. C.; De Almeida, A. T. (2011). Ecoanalysis of variable-speed drives for flow regulation in pumping systems, IEEE Transactions on Industrial Electronics, Vol. 58, No. 6, 2117-2125, doi:10.1109/TIE.2010.2057232

[3] Lovrec, D.; Kastrevc, M.; Ulaga, S. (2009). Electro-hydraulic load sensing with a speedcontrolled hydraulic supply system on forming-machines, The International Journal of Advanced Manufacturing Technology, Vol. 41, No. 11-12, 1066-1075, doi:10.1007/s00170-008-1553-y

[4] Wang, W., Wang, B. (2016). An energy-saving control strategy with load sensing for electrohydraulic servo systems, Strojniski vestnik - Journal of Mechanical Engineering, Vol. 62, No. 12, 709-716, doi:10.5545/sv-jme.2016.3685

[5] Huang, J.; Yan, Z.; Quan, L.; Lan, Y.; Gao, Y. (2015). Characteristics of delivery pressure in the axial piston pump with combination of variable displacement and variable speed, Proceedings of the Institution of Mechanical Engineers, Part I: Journal of Systems and Control Engineering, Vol. 229, No. 7, 599-613, doi:10.1177/0959651815578967

[6] Tašner, T., Les, K., Tič, V., Lovrec, D. (2014). Energy efficiency of different electrohydraulic drives, $9^{\text {th }}$ International Fluid Power Conference, RWTH University, IFAS, 14-25 
[7] Man, Z., Ding, F., Ding, C., Liu, S. (2015). Study of an energy regeneration system with accumulator for hydraulic impulse testing equipment, Strojniski vestnik - Journal of Mechanical Engineering, Vol. 61, No. 3, 196-206, doi:10.5545/sv-jme.2014.2138

[8] Detiček, E.; Kastrevc, M. (2016). Design of Lyapunov based nonlinear position control of electrohydraulic servo systems, Strojniski vestnik - Journal of Mechanical Engineering, Vol. 62, No. 3, 163-170, doi:10.5545/sv-jme.2015.2921

[9] Žilić, T.; Kasać, J.; Essert, M.; Novaković, B.; Šitum, Ž. (2012). Performance comparison of different control algorithms for robot manipulators, Strojarstvo - Journal for the Theory and Application in Mechanical Engineering, Vol. 54, No. 5, 399-407

[10] Zupan, H.; Herakovic, N.; Starbek, M.; Kusar, J. (2016). Hybrid algorithm based on priority rules for simulation of workshop production, International Journal of Simulation Modelling, Vol. 15, No. 1, 29-41, doi:10.2507/IJSIMM15(1)3.319

[11] Wang, J. F.; Kang, W. L.; Zhao, J. L.; Chu, K. Y. (2016). A simulation approach to the process planning problem using a modified particle swarm optimization, Advances in Production Engineering \& Management, Vol. 11, No. 2, 77-92, doi:10.14743/apem2016.2.211

[12] Tašner, T.; Tič, V.; Lovrec, D. (2013). Advanced control concepts suitable for energy efficient hydraulic systems, SIMULTECH 2013, $3^{\text {rd }}$ International Conference on Simulation and Modeling Methodologies, Technologies and Applications, Reykjavík, 3-11

[13] Petrović, I.; Pavlic, T.; Čikić, A. (2014). The approach to stability determination of single axis positioning regulation for the model of TTT manipulator, Technical Gazette, Vol. 21, No. 5, 1041-1046

[14] Basri, M. A. M..; Danapalasingam, K. A.; Husain, A. R. (2014). Design and optimization of backstepping controller for an underactuated autonomous quadrotor unmanned aerial vechicle, Transactions of FAMENA, Vol. 38, No. 3, 27-44

[15] Lovrec, D.; Kastrevc, M. (2011). Modelling and simulating a controlled press-brake supply system, International Journal of Simulation Modelling, Vol. 10, No. 3, 133-144, doi:10.2507/IJSIMM10(3)3.184

[16] Xu, M.; Ni, J.; Chen, G. (2014). Dynamic simulation of variable-speed valve-controlled-motor drive system with a power-assisted device, Strojniski vestnik - Journal of Mechanical Engineering, Vol. 60, No. 9, 581-591, doi:10.5545/sv-jme.2013.1532

[17] Casoli, P.; Pompini, N.; Riccò, L. (2015). Simulation of an excavator hydraulic system using nonlinear mathematical models, Strojniski vestnik - Journal of Mechanical Engineering, Vol. 61, No. 10, 583-593, doi:10.5545/sv-jme.2015.2570

[18] Nauparac, D. B.; Pršić, D. H.; Miloš, M. V.; Todić, I. S. (2015). Different modelling technologies of hydraulic load simulator for thrust vector control actuator, Technical Gazette, Vol. 22, No. 3, 599-606, doi:10.17559/TV-20140621063240

[19] Pandilov, Z.; Milecki, A.; Nowak, A.; Gorski, F.; Grajewski, D.; Ciglar, D.; Klaić, M.; Mulc, T. (2016). Virtual modelling and simulation of a CNC machine feed drive system, Transactions of FAMENA, Vol. 39, No. 4, 37-54

[20] Herakovič, N., Duhovnik, J.; Šimic, M. (2015). CFD simulation of flow force reduction in hydraulic valves, Technical Gazette, Vol. 22, No. 2, 453-463, doi:10.17559/TV-20141128090939

[21] Lovrec, D.; Tic, V.; Tasner, T. (2015). Simulation-aided determination of an efficiency field as a basis for maximum efficiency-controller design, International Journal of Simulation Modelling, Vol. 14, No. 4, 669-682, doi:10.2507/IJSIMM14(4)9.324 